\title{
Gender Differences in Intentions to use a Personal Carbon Trading System
}

\author{
Alex Hendry ${ }^{1}$, Bruce Armstrong ${ }^{2}$, Garry Egger $^{3}$, Gary Webb $^{4}$, William Smart ${ }^{5}$ \\ ${ }^{1}$ School of Business and Tourism, Southern Cross University \\ Southern Cross Drive \\ Bilinga, Old, 4225, Australia \\ Email:alex.hendry@scu.edu.au \\ ${ }^{2}$ School of Business and Tourism, Southern Cross University \\ Hogbin Drive \\ Coffs Harbour, NSW, 2450, Australia \\ Email: bruce.armstrong@scu.edu.au \\ ${ }^{3}$ School of Health and Human Sciences, Southern Cross University \\ Lismore, NSW, 2482, Australia \\ Email:eggergj@gmail.com \\ ${ }^{4}$ School of Health and Human Sciences, Southern Cross University \\ Hogbin Drive \\ Coffs Harbour, NSW, 2450, Australia \\ Email: g.webb.23@student.scu.edu.au \\ ${ }^{5}$ School of Business and Tourism, Southern Cross University \\ Southern Cross Drive \\ Bilinga, Qld, 4225, Australia \\ Email: bill.smart@scu.edu.au
}

\begin{abstract}
Personal carbon trading systems (PCTS) have been hypothesized as one of the measures needing to be considered to combat global warming and reduce carbon emissions (references here). The research described in this paper examines baseline data collected as part of the Norfolk Island Carbon Health Evaluation (NICHE) project. The project aims to examine links between obesity related conditions and individuals' understanding of their carbon footprint. A personal carbon monitoring system was rolled out on the Island mid 2013 that allows users to review their carbon outputs against a baseline calculated from the initial survey. The analysis presented here examines the differences between males and females attitudes towards the adoption of PCTS from a baseline survey conducted prior to the roll out of the system. The analysis of the model by gender revealed that 'Health Consciousness' and 'Environmental Concerns' were significant predictors for both genders. 'Optimism' was also identified by both genders to be significant, but it was found to explain double the amount of variance for males than females. Whereas, 'Self Heath Evaluation' was found to only be a significant predictor of female attitudes towards a PCTS. Surprisingly, 'Environmental Action' was found not to be a significant predictor to either genders attitudes towards the adoption of PCTS.
\end{abstract}

Keywords: Personal Carbon Trading, Personal Carbon Trading System, Climate Change, Environmental Behaviours, Obesity, Gender Differences 


\section{Introduction}

Increased global levels of obesity and greenhouse gas (GHG) pollution causing climate change are two currently interrelated world dilemmas. ${ }^{1,2}$ Obesity considerably increases the risks of an individual suffering chronic disease and directly affects the individual's total well-being. ${ }^{3}$ GHG pollution has not just the potential to affect the world's environment, but additionally presents one of the greatest threats to public health in the 21 st century. ${ }^{4}$ Although not widely canvassed in literature the increase in both obesity and GHG pollution would seem to have a common causality in human behaviours, e.g. personal inactivity by making use of carbon emitting fossil-fuel powered transport; consumption of high energy-dense, refined foods etc.. ${ }^{5,6,7}$ Due to the aforementioned common causality, it's reasonable to suggest that an intervention directed at behavioural change reducing GHG pollution may prove beneficial in responding to both climate change and increased levels of obesity by encouraging the use of more active transport and the intake of a more wholesome diet, with a reduction in highly processed food.

Carbon emissions trading, at the corporate and national level is the currently preferred macroeconomic method adopted to reduce GHG pollution and could have the effect of addressing these issues by altering the economic levers changing corporate, and to a lesser degree, individual's behaviours. Corporate GHG pollution only accounts for $50-60 \%$ of total emissions. It has been proposed that Personal Carbon Trading (PCT) be introduced to change the microeconomics at the individual's level. ${ }^{8}$

D. Flemming ${ }^{9}$ proposed Personal Carbon Allowances (PCAs) in the United Kingdom as an equitable means of reducing carbon emissions from households and individuals within the population. A PCT scheme as a part of PCA developed at Oxford University $^{10}$ was endorsed in part by the British Parliament. It was recommended that it be re-assessed at some future date mainly due to a lack of confidence in its political acceptability. ${ }^{11}$

The proposed PCT would operate by annually assigning to each individual an equal number of tradable energy units, that is, their personal carbon allowance. The number of units is based on $40 \%$ of the total budget (that includes both corporate and personal quotas) using a national budgetary council. Each of these units is equivalent to 1 kilogram of carbon released to the atmosphere by energy usage. These units match the definition of a carbon credit under the Kyoto accord $^{12,13}$ and therefore reductions in the national population's usage could be demonstrated. Trade of units would then be carried out via either existing credit cards or through a carbon card system. By being frugal, individuals could sell any excess personal carbon credits back into the market thereby providing them with a financial gain. Individuals who overuse their quota would be required to pay a premium price for each additional energy unit used. ${ }^{8}$

Fossil fuel powered transportation is one of the major contributors of carbon pollution and associated climate change ${ }^{13}$. Individuals' dependence on fossil fuel powered transportation and the related reduction in active forms of transport is also viewed as a major contributor to the obesity epidemic. ${ }^{15,16,17,18}$

The increase in the global levels of obesity has been linked to the rise in diabetes ${ }^{19}$, increased risk of cancer of the oesophagus, kidney, pancreas, gall bladder, breast, thyroid, ovary, cervix, endometrium and prostate, in addition to multiple myeloma and Hodgkin's lymphoma. ${ }^{20}$

Theoretically use of a PCT may well encourage a reduction in the usage of fossil fuel powered transportation and increase in participation of active types of transport (e.g. walking/cycling), due to the increased 'real' expense of energy usage. PCT might additionally encourage reduced consumption of meat and highly processed/refined food and drink products which are associated with an increased incidence of obesity, chronic disease and environmental impact due to the additional greenhouse gas pollution related to production and delivery of these products.

An issue with the present status of PCT is the impracticality of trialling a system on an entire country prior to its introduction. This is due to a lack of information about its political acceptability along with insufficient practical operational detail for this kind of system. $^{21}$ The idea however does lend itself to be evaluated within a 'closed' system, such as an island, where environmental attitudes, health metrics and operational detail can be accurately measured. The problem however is to find an island having an advanced enough economy, yet remote enough to be relatively closed, and sufficiently small for testing purposes within a reasonable research budget. 
One such location is Norfolk Island off the east coast of Australia. This island was chosen as it is an ideal location to test the political acceptability, attitudes of the population towards, possible health benefits derived from and the operational requirements of Personal Carbon Trading in a closed island community.

\section{Background}

\subsection{Study population}

Norfolk Island is home to a population of approximately 1,600 residents $^{22}$ and is a self-governing Australian protectorate located 1,500 kilometres from the east coast of Australia and 1,200 kilometres from the northern tip of New Zealand. Norfolk is a relatively small volcanic island measuring approximately 40 square kilometres. The economy is predominantly based on tourism with an average of 24,000 visitors annually.

On Norfolk Island the cost of most goods, particularly electricity and fuel, are significantly greater than on the Australian mainland. Considering the small size of the island, locals need only drive small distances, many of which could simply be walked or cycled.

Due to the expensive costs associated with importation of common household items and the restricted waste disposal facilities on the island, residents are accustomed to reusing items many times before they are disposed of.

General observation suggests that due to cost residents of Norfolk Island are already vigilant in their usage of energy resources and further reductions in GHG pollution will come from new developments in technologies or changes in behaviours relating to consumption (including food) and methods of transportation. Therefore, a targeted intervention such a PCT system designed to further reduce GHG pollution might encourage reductions by making changes to residents' consumption patterns and active transport behaviours.

\subsection{The NICHE project}

The Norfolk Island Carbon Health Evaluation (NICHE) project was established in 2011 with the following primary goals:
- assess whether personal carbon allowances are effective in reducing an individual's carbon footprint and what impact this has on health behaviours associated with obesity;

- assess the political acceptability of introducing a personal carbon trading system into a population as a tool for reducing greenhouse gases; and

- to explore the relationships between positive health behaviours and pro-environmental behaviours.

This paper explores the intentions of individuals to use a Personal Carbon Trading System (PCTS), in particular the paper focuses on the differences in attitudes based on gender. Data collected via survey covered respondents' attitudes towards their health and well-being, the environment, carbon footprint and climate change.

\subsection{Conceptual model}

As a PCTS falls under the definition of an information system the literature concerning information system success was invaluable in the development of the conceptual model and deciding how to test it. A number of models that measure information system success have been proposed over the last thirty years including the DeLone and McLean Information System Success model, ${ }^{23,24,25}$ the Unified Theory of Acceptance and Use of Technology (UTAUT) model, ${ }^{26}$ the Technology Acceptance Model (TAM) $)^{27,28,29}$ and the Technology Acceptance Model 2 (TAM2) ${ }^{30}$. TAM2 was selected as the basis of the conceptual model as it offered the most insight to this project.

While the constructs from the conceptual model used for the research described in this paper do not follow the relationship paths between the variables in TAM2, insight into information system success and in particular the effect that attitudes have on information system success were developed from $\mathrm{TAM} 2^{30}$. Figure 1 following, hypothesizes that an individual's PCTS usage intentions are influenced by:

- Self-health evaluation - Information on an individual's self-evaluation of their own health and weight Attitudes and behaviours towards healthIndividuals who have positive attitudes and behaviours about health and weight management and who exercise regularly are more likely to have a positive $\mathrm{PCT}$ usage intentions

- Attitudes and behaviours towards the environment - Individuals who have positive attitudes and 
behaviours towards the environment are more likely to have a positive PCTS usage intentions Attitudes and behaviours towards carbon emissions and climate change - Individuals who have positive attitudes and behaviours towards their carbon footprint, reduction of their carbon emissions and are concerned about climate change are more likely to have positive PCTS usage intentions.

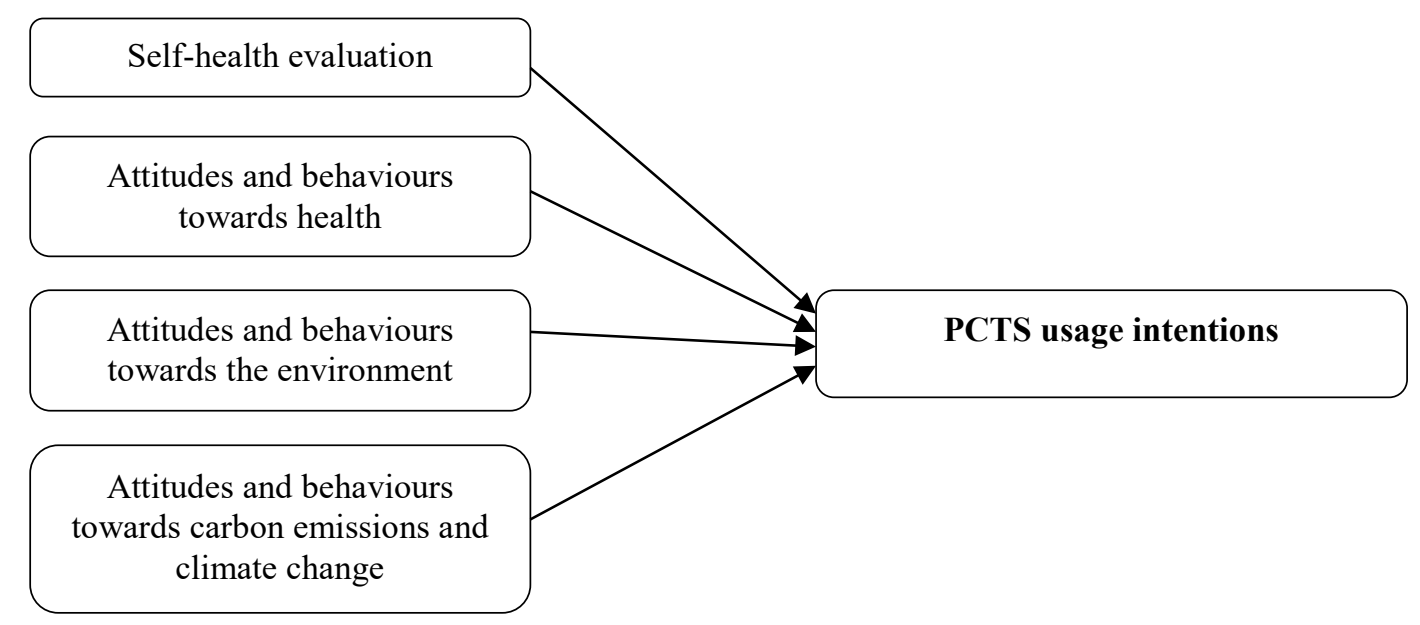

Figure. 1. NICHE Conceptual Model - Hypothesized Influences on PCTS Usage Intentions.

\section{Method}

\subsection{The NICHE survey}

A survey was sent to residences on Norfolk Island to collect baseline data that could be used to determine attitudes towards use of PCTS and also to collect general demographic information about individual respondents and their households. The survey was an exploratory study looking to identify predictors of attitudes towards PCTS. Given there were really no other direct studies the researchers could draw upon to formulate the scales, the measures of PCTS acceptance were developed from items measuring information success. The other items on the survey were included to measure attitudes towards global warming and climate change, environmental actions, general diet and nutrition, and attitudes towards health.

"The survey contained the following sections:

- General information (questions A1 - A13) general information about the respondents (including gender) and their household, their health and their beliefs about their own and their household's carbon foot print

- Attitudes (questions B1 - B13) - the respondents and their household's attitudes and towards health, the environment, carbon emissions and climate change
- Behaviours (questions B14 - B19) - the respondents and their household's behaviours towards consumption and climate change

- Physical activity (questions C1 - C15) - the respondents and their household's physical activity

- Nutrition (questions D1 - D31) - the respondents diet and nutrition

- Personal carbon trading (questions E1 - E10) - the respondents' attitudes and beliefs about a personal carbon trading systems

- Demographic data (questions F1 - F28) - general demographic information about the respondent including age, gender, income, education, height, weight, health, home ownership and motor vehicle ownership". 31

The NICHE survey collection resulted in 423 useable responses. Comparison of the number of responses to information from the 2011 census of the island $^{31}$ shows that the 423 responses represent over $60 \%$ of the occupied households on Norfolk Island. As stated previously, the survey contained questions related to both the household and the individual respondent's attitudes. The responses to the questions seeking an individual's response represented over $30 \%$ of Norfolk Island's adult population (over 18 years of age).

Questions in the survey were arranged in sections that reflected the constructs in the conceptual model. 
The same set of questions were used in the analysis described in a previous paper ${ }^{31}$ that describes a model based on the complete data set (not moderated by gender).

- "Questions B1-B13-included as measures of the attitudes and behaviours towards health, attitudes and behaviours towards the environment and attitudes and behaviours towards carbon emissions and climate change components of the conceptual model.

- Questions B14-B19-included as measures of the attitudes and behaviours towards the environment component of the conceptual model.

- Questions A9, A10, A12 and C1 - included as measures of the self-health evaluation component of the conceptual model.

- Questions E1 - E10 - included to measure users' usage intentions towards a PCTS. The ten questions in this section were adapted from scales used by researchers examining user information system satisfaction and technology acceptance. The questions in this section are intended to measure the information needed for the dependent variable PCTS usage intentions of the 'information systems' component of the NICHE study".

\section{Testing the Conceptual Model}

The initial examination of the relationships between variables was undertaken using correlation analysis with the directionality of the relationships examined using linear regression analysis.

Following the correlation analysis, Exploratory Factor Analysis (EFA) was run on the blocks of variables expected to have an underlying factor structure as per the conceptual model. The EFA examining the block of variables (Questions E1-E10) that were used to form the dependent variable resulted in a single factor, 'Usage Intentions Towards a PCTS'. The EFA run on the other blocks of variables resulted in five factors being identified rather than the four proposed in the conceptual model.

To clarify this all factors were renamed as following, 'Self-Health Evaluation' (Questions A9, A10, A12, C1), 'Health Consciousness', (Questions B3, B8, B9) 'Environmental Action' (Questions B14 - B19), 'Optimism' (Questions B2, B4, B6), B11, B12) and 'Environmental Consciousness' (Questions B1, B5, B7, $\mathrm{B} 13)$. Table 1 below displays the factors and the variables/questions
Correlation analysis was also run on the factors that were derived from the EFA prior to the regression analysis. The blocks of variables entered into the linear regression model were based on the variables identified underlying each of the factors. The variables comprising each of the factors that were extracted from the EFA were entered as blocks to predict the total variance in 'Usage Intentions Towards a PCTS' and identify which variables in each block were significant. The regression model was then examined by moderating inputs based upon the respondent's gender.

\subsection{Males}

The summary in Table 2 below shows that among male respondents, $38.3 \%$ of the total variance in 'Usage Intentions towards a PCTS' was predicted by the 5 blocks of variables entered to the model. 'Self-Health Evaluation' and 'Environmental Action' were not significant. The 'Health Consciousness' block of variables was close to the $95 \%$ confidence interval (sig $\mathrm{F}=0.052)$ and explained $8.2 \%$ of the total variance in 'Usage Intentions towards a PCTS'. Both 'Optimism' and 'Environmental Consciousness' were significant at the $99 \%$ confidence interval and explained $9.7 \%$ and $12.1 \%$ of the variance respectively.

The beta values showing the significance of the individual variables in each block are shown in the Appendix (Figure 2).

In the 'Self-Health Evaluation' block, variable C1 "How often do you engage in leisure time physical activity for the sole purpose of improving or maintaining your health" was statistically significant ( $p$ $=0.033)$. No variables in the 'Environmental Action' block were significant although variable B17 "I look to buy second hand over brand new" was close $(p=$ 0.063). However, neither of these two blocks of variables explained a significant amount of variance in 'Usage Intentions towards a PCTS'. Of the blocks of variables that were significant the following individual variables were identified in the coefficient matrix as being significant at the $95 \%$ confidence interval or greater:

- 'Health Consciousness' - variable B9 "I am confident I could maintain a healthy body weight if I wanted to" $(p=0.007)$

- 'Optimism' - variable B2 "Technology will solve future environmental problems" $(p=0.037)$ and 
variable B6 "A financial incentive would encourage me to reduce my environmental impact" $(p=0.003)$
- 'Environmental Consciousness' - variable B1 "I buy environmentally friendly products as much as $I$ can" $(p=0.041)$ and variable B13 "I am worried about climate change" $(p=0.028)$

Table 1 Factors and Variables

\begin{tabular}{|c|c|}
\hline Factor & Variable / Comment \\
\hline \multirow[t]{5}{*}{ Self-Health Evaluation } & Significant for Females. \\
\hline & A9 - Do you generally consider your health to be... \\
\hline & A10 - How would you best describe yourself? \\
\hline & $\begin{array}{l}\text { A12.-. Compared to others on the island of similar age and gender do you consider your } \\
\text { body weight to be..... }\end{array}$ \\
\hline & $\begin{array}{l}\text { C1 - How often do you engage in leisure time physical activity physical activity for the } \\
\text { sole purpose of improving or maintaining your health }\end{array}$ \\
\hline \multirow{4}{*}{ Health Consciousness } & Significant for Females and Males. \\
\hline & B3 - Being overweight can have serious health effects \\
\hline & B8 - I always try to eat healthy food \\
\hline & B9 - I am confident I could maintain a healthy body weight if I wanted to \\
\hline \multirow{7}{*}{ Environmental Action } & Significant for Females and Males. \\
\hline & B14 - I turn the tap off when cleaning my teeth \\
\hline & B15 - I turn lights off when not in use \\
\hline & B16 - I sort my rubbish \\
\hline & B17 - I look to buy second hand over brand new \\
\hline & B18 - I consciously try to reduce waste and recycle \\
\hline & B19 - I buy local produce, even if imported is cheaper \\
\hline \multirow{4}{*}{ Optimism } & Significant for Females and Males. \\
\hline & B2 - Technology will solve future environmental problems \\
\hline & B4 - Obesity will be solved in the future by medical advances \\
\hline & B6 - A financial incentive would encourage me to reduce my environmental impact \\
\hline \multirow{5}{*}{ Environmental Consciousness } & Not significant for either gender. \\
\hline & B1 - I buy environmentally friendly products as much as I can. \\
\hline & B5 - It is important for me to have a low carbon footprint \\
\hline & B7 - Collectively, households can reduce the impacts of greenhouse gas emissions \\
\hline & B13 - I am worried about climate change \\
\hline \multirow[t]{11}{*}{ Usage Intentions Towards a PCTS } & Dependant Variable for both genders. \\
\hline & E1 - Being able to measure my carbon footprint is important to me \\
\hline & E2 - Most people would accept a PCT system as a tool for improving the environment \\
\hline & E3 - A PCT system would encourage me to reduce my carbon footprint \\
\hline & E4 - A PCT system would encourage me to walk or cycle more and drive less \\
\hline & E5 - People who reduce their carbon footprint should be rewarded in some way \\
\hline & E6 - People with a greater carbon footprint should have to pay for it in some way \\
\hline & E7 - A PCT system would encourage me to eat more healthy, locally grown produce \\
\hline & E8 - A PCT system would be useful for me to help monitor my environmental impact \\
\hline & E9 - Comparing my carbon usage to the average would influence my consumption habits \\
\hline & E10 - There is a strong link between a person's carbon footprint and their health \\
\hline
\end{tabular}


Table 2 Regression Modelling - Males

\begin{tabular}{|c|c|c|c|c|c|c|c|c|c|}
\hline \multirow[t]{2}{*}{ Model } & \multirow{2}{*}{$\frac{\mathrm{R}}{\text { Male }}$} & \multirow[t]{2}{*}{ R Square } & \multirow{2}{*}{$\begin{array}{l}\text { Adjusted R } \\
\text { Square }\end{array}$} & \multirow{2}{*}{$\begin{array}{l}\text { Std. Error of } \\
\text { the Estimate }\end{array}$} & \multicolumn{5}{|c|}{ Change Statistics } \\
\hline & & & & & R Square Change & F Change & $\mathrm{dfl}$ & $\mathrm{df} 2$ & Sig. F Change \\
\hline 1 & $.196^{\mathrm{a}}$ & .038 & .008 & .98160 & .038 & 1.269 & 4 & 127 & .286 \\
\hline 2 & $.347^{b}$ & .120 & .055 & .95800 & .082 & 2.267 & 5 & 122 & .052 \\
\hline 3 & $.406^{\mathrm{c}}$ & .165 & .057 & .95722 & .045 & 1.033 & 6 & 116 & .407 \\
\hline 4 & $.512^{d}$ & .262 & .144 & .91178 & .097 & 4.950 & 3 & 113 & .003 \\
\hline 5 & $.619^{\mathrm{e}}$ & .383 & .258 & .84877 & .121 & 5.350 & 4 & 109 & .001 \\
\hline $\begin{array}{l}\text { a. Predi } \\
\text { b. Pred } \\
\text { c. Predi } \\
\text { d. Pred } \\
\text { e. Predi }\end{array}$ & $\begin{array}{l}\text { onstant } \\
\text { onstant } \\
\text { onstant } \\
\text { onstant } \\
\text { onstant }\end{array}$ & $\begin{array}{l}0, \mathrm{C} 1, \mathrm{~A} 9, \\
0, \mathrm{C} 1, \mathrm{~A} 9, \\
0, \mathrm{C} 1, \mathrm{~A} 9, \\
0, \mathrm{C} 1, \mathrm{~A} 9, \\
0, \mathrm{C} 1, \mathrm{~A} 9,\end{array}$ & $\begin{array}{l}\mathrm{B} 11, \mathrm{~B} 8, \mathrm{~B} \\
\mathrm{~B} 11, \mathrm{~B} 8, \mathrm{~B} \\
\mathrm{~B} 11, \mathrm{~B} 8, \mathrm{~B} \\
\mathrm{~B} 11, \mathrm{~B} 8, \mathrm{~B}\end{array}$ & $\begin{array}{l}\mathrm{B} 12, \mathrm{~B} 9 \\
\mathrm{~B} 12, \mathrm{~B} 9, \mathrm{~B} 16, \\
\mathrm{~B} 12, \mathrm{~B} 9, \mathrm{~B} 16, \\
\mathrm{~B} 12, \mathrm{~B} 9, \mathrm{~B} 16,\end{array}$ & $\begin{array}{l}\text { 17, B19, B14, B18, } \\
\text { 17, B19, B14, В18, } \\
17, \mathrm{~B} 19, \mathrm{~B} 14, \mathrm{~B} 18,\end{array}$ & $\begin{array}{l}15 \\
15, \mathrm{~B} 2, \mathrm{~B} 4, \\
15, \mathrm{~B} 2, \mathrm{~B} 4\end{array}$ & $\mathrm{~B} 13$ & B7, & \\
\hline
\end{tabular}

Table 3 Regression Modelling - Females

\begin{tabular}{|c|c|c|c|c|c|c|c|c|c|}
\hline \multirow[t]{2}{*}{ Model } & $\mathrm{R}$ & \multirow[t]{2}{*}{ R Square } & \multirow{2}{*}{$\begin{array}{l}\text { Adjusted R } \\
\text { Square }\end{array}$} & \multirow{2}{*}{$\begin{array}{l}\text { Std. Error of } \\
\text { the Estimate }\end{array}$} & \multicolumn{5}{|c|}{ Change Statistics } \\
\hline & Female & & & & R Square Change & F Change & df1 & $\mathrm{df} 2$ & Sig. F Change \\
\hline 1 & $.294^{\mathrm{a}}$ & .087 & .066 & .83501 & .087 & 4.122 & 4 & 174 & .003 \\
\hline 2 & $.406^{\mathrm{b}}$ & .165 & .120 & .81011 & .078 & 3.172 & 5 & 169 & .009 \\
\hline 3 & $.442^{\mathrm{c}}$ & .195 & .121 & .80984 & .030 & 1.019 & 6 & 163 & .415 \\
\hline 4 & $.490^{\mathrm{d}}$ & .240 & .155 & .79406 & .045 & 3.181 & 3 & 160 & .026 \\
\hline 5 & $.597^{\mathrm{e}}$ & .357 & .266 & .74002 & .116 & 7.056 & 4 & 156 & .000 \\
\hline $\begin{array}{l}\text { a. Predi } \\
\text { b. Pred } \\
\text { c. Predi } \\
\text { d. Pred } \\
\text { e. Predi }\end{array}$ & $\begin{array}{l}\text { Constant), } \\
\text { Constant), } \\
\text { Constant), } \\
\text { Constant), } \\
\text { Constant), }\end{array}$ & $\begin{array}{l}0, \mathrm{C} 1, \mathrm{~A} 9, \\
0, \mathrm{C} 1, \mathrm{~A} 9, \\
, \mathrm{C} 1, \mathrm{~A} 9, \\
0, \mathrm{C} 1, \mathrm{~A} 9, \\
0, \mathrm{C} 1, \mathrm{~A} 9,\end{array}$ & $\begin{array}{l}\mathrm{B} 11, \mathrm{~B} 8, \mathrm{~B} \\
\mathrm{~B} 11, \mathrm{~B} 8, \mathrm{~B} 3 \\
\mathrm{~B} 11, \mathrm{~B} 8, \mathrm{~B} \\
\mathrm{~B} 11, \mathrm{~B} 8, \mathrm{~B}\end{array}$ & $\begin{array}{l}\text { В12, B9 } \\
312, \text { B9, B16, } \\
\text { В12, B9, B16, } \\
\text { В12, B9, B16, }\end{array}$ & $\begin{array}{l}17, \mathrm{~B} 19, \mathrm{~B} 14, \mathrm{~B} 18 \\
317, \mathrm{~B} 19, \mathrm{~B} 14, \mathrm{~B} 18 \\
317, \mathrm{~B} 19, \mathrm{~B} 14, \mathrm{~B} 18\end{array}$ & $\begin{array}{l}315 \\
\text { B15, B2, B4 } \\
\text { B15, B2, B4 }\end{array}$ & B13 & , B7, & \\
\hline
\end{tabular}

\subsection{Females}

In the multiple regression model for women, $35.6 \%$ of the total variance in 'Usage Intentions towards a PCTS' was predicted by the 5 blocks of variables, with 4 of the 5 being significant. This is displayed in Table 3 above. 'Environmental Action' was the only block that was not significant.

Of the 4 blocks that were significant 'Optimism' explained 4.5\%, 'Health Consciousness' explained $7.8 \%$, 'Self Health Evaluation' explained $8.7 \%$ and 'Environmental Consciousness' explained $11.6 \%$ of the variance in 'Usage Intentions towards a PCTS'.

The beta values showing the significance of the individual variables in each block are shown in the Appendix (Figure 3).

The coefficient matrix showed that none of the individual variables in the 'Health Consciousness' or the
'Environmental Action' blocks were significant. Of the other blocks of variables that were significant the following variables were identified in the coefficient matrix as being significant at the $95 \%$ confidence interval or greater:

- 'Optimism' - variable B6 "A financial incentive would encourage me to reduce my environmental impact" $(p=0.020)$

- $\quad$ 'Self-Health Evaluation' - variable A9 "Do you generally consider your health to be" $(p=0.020)$ and variable $\mathrm{C} 1$ "How often do you engage in leisure time physical activity for the sole purpose of improving or maintaining your health" $(p=0.044)$

- $\quad$ 'Environmental Consciousness' - variable B1 "I buy environmentally friendly products as much as I can" $^{\prime \prime}(p=0.019)$ and variable B13 "I am worried about climate change" $(p=0.036)$ 


\section{Conclusion}

A slightly higher percentage of the total variance in 'Usage Intentions towards a PCTS' was explained in the model of responses from males $(38.3 \%)$ than females $(35.6 \%)$. However, the percentages are very similar, which seems to indicate there were no major differences between the attitudes of males and females towards their intentions to use a PCTS.

However, the 'Self Health Evaluation' block of variables explained $8.7 \%$ of the total variance in the model for females and was found to be not significant in the regression model for males. The reason for this difference is not clear, but, literature does show males use health services less often than females, their health is poorer and their mortality rates are higher. ${ }^{32,33,34,35,36}$ The exact reasons for this disparity in the use of health services is not clear however it is thought that due to masculine stereotypes and cultural reasons males are less interested or concerned about their health and less likely to seek help than females for health related problems. ${ }^{34,35,36}$ On face-value, the analysis results seem to be supporting what the literature is telling us about the attitude of men towards their own health

The responses from males to the questions in the 'Optimism' block of variables explained more than twice the amount of variance in 'Usage Intentions towards a PCTS' than the responses to these items from females $-9.7 \%$ for males compared to $4.5 \%$ for females. It is of interest that the analysis of the responses from males found two variables significant (B2 - "Technology will solve future environmental problems" and B6 - "A financial incentive would encourage me to reduce my environmental impact"), whereas the analysis of responses from females identified only variable B6 as significant $(\mathrm{p}=0.020)$. This tends to indicate while both genders express interest in financial incentives as an influence on 'Usage Intentions towards a PCTS' a further influence on males is their belief in science and technology (perhaps via a PCTS) to solve the problems associated with climate change and global warming.

The variance explained by Health Consciousness (males $8.2 \%$ - females $7.8 \%$ ) the 'Environmental Consciousness' (males 12.1\% - females 11.6\%) blocks of variables was similar for both genders. It should be noted that 'Environmental Consciousness' explained the highest level of variance in 'Usage Intentions towards a
$\underline{P C T S}^{\prime}$ of any of the blocks of variables for both males and females.

The fact that the relationship between 'Environmental Action' and 'Usage Intentions towards a $\underline{P C T S}$ ' wasn't significant in the analysis of the responses from either gender is noteworthy. It was assumed by the researchers that individuals who exhibit positive environmental actions would have positive usage intentions towards a PCTS. After consideration, the researchers surmised that the positive environmental actions displayed by the majority of Norfolk Islanders was primarily due to economic reasons, no matter what their usage intentions towards a PCTS. Owing to the geographic location of Norfolk Island all products must be transported to the island and electricity, fuel and imported products are a great deal costlier than on mainland Australia. Due to these increased costs and the relatively low incomes of the Island's residents, they are a great deal more likely to have solar electricity and solar hot water systems, and engage in positive environmental actions/behaviours irrespective of their usage intentions towards PCTS.

The researchers believed that 'Environmental Action' would be a predictor of 'Usage Intentions towards a PCTS', hence its inclusion on the model. It is thought it may still be a significant predictor when attitudes are measured in the post-implementation phase of the project. So while it is interesting to note its place in the analysis of the baseline model, this variable should still be considered by researchers, especially when examining the model in different populations. Analysis of the post-implementation data is expected to reveal additional information including the possibility of non-significant constructs becoming significant as the project hopes to also raise awareness of environmental issues among the population on the Island.

The NICHE researchers recognize that the analyses forming the basis of this paper were conducted from a baseline survey of data on individual and household behaviours and attitudes prior to the roll-out of a PCTS on the Island. The significant predictors of 'Usage Intentions towards a PCTS identified in this paper are expected to change once the users have experience with the PCTS and grasp how their actions and behaviours can affect their carbon footprint. The relationships among the variables reported within this paper will be revisited to examine whether actually using a PCTS 
alters their behaviours and attitudes towards the environment and their own health.

\section{Limitations of the study}

As Norfolk Island is a relatively closed system it is well-suited for the NICHE research project but it also creates limitations. While the inhabitants are reasonably representative of other developed locations the Island's geographic isolation can reasonably be anticipated to have an impact on attitudes and behaviours towards the environment, climate change and health. All products must be transported to Norfolk Island and as a result, fuel and imported food are a great deal costlier than on the mainland.

Electricity is also very expensive on Norfolk Island compared to mainland Australia and other locations in developed countries. All infrastructure to support the grid and fuel for the generators must arrive by ship making it expensive to produce and roll-out to residents. Therefore, most households on Norfolk Island have some form of solar or wind generators and/or solar hot water systems. However, this would seem to a result of economic necessity more so than concerns about global warming.

Therefore, the relationship between

'Environmental Action' and 'Usage towards a PCTS' evident from the models explored in this paper may be driven by necessity, as well as, or even more so, than concerns about the environment.

The baseline survey undertaken was administered to gather both household data and individual data, and as such had several limitations:

- Since only one member of each household was required to fill out the survey it has to be recognized that the attitudes and beliefs reflect that person's views rather than the views held by all members of the household.

- The age distribution of survey respondents was similar to the NICHE 2011 census $^{22}$ however there were some differences, particularly in the $20-29$ year, age band.

- A higher percentage of females (59.8\%) filled out the survey for their household than males $(40.2 \%)$.

- The anonymity of the NICHE survey did not allow researchers to follow up individual respondents or households with further questions. For example, it would have been interesting to follow up with respondents about 'Environmental Action' given it was not significant in either model.

However, due to the high response rate $(n=423)$, the survey is held to be representative of the views of the broader population of Norfolk Island.

The unique nature of the NICHE study also makes it difficult to identify other research of this nature for comparative purposes. As a result, the conceptual model and the scales developed to measure the constructs were tested for the first time in this study. The construct 'Optimism' for example was identified from the research itself and was not identified in any related literature. This suggests that there may be other constructs that could affect usage intentions towards PCTS that were not considered by the NICHE researchers.

\section{Implications for Future Research}

There has been much research into:

- the link between carbon emissions and climate change,

- individual beliefs associated with the causes of climate change,

- the political acceptability of Persona Carbon Trading, and

- the causes and links between health and obesity.

A comprehensive review of the literature was however, unable to identify research into how all of these factors fit together and impact on an individual's usage intention towards PCTS. The researchers believe that the NICHE study is the first study of its kind to explore how individual's attitudes and behaviours influence their usage intentions towards a PCTS. This study is therefore relevant to any future research within these areas and provides future researchers a solid basis to help expand the relationship between these attitudes and behaviours and their effect on PCTS.

Since this is apparently the first research of this type to determine usage intentions towards PCTS it will provide researchers with a model as a foundation for future research. The scales that have been developed to evaluate the constructs of the conceptual model will also supply a starting point for future research of this nature. 


\section{References}

1. I. Roberts, How the obesity epidemic is aggravating global warming, New Scientist, 2610( 21) (2007).

2. G. Egger and B.Swinburn, Planet Obesity: How we're eating ourselves and the planet to death, (Allen and Unwin, 2011).

3. Foresight, Tackling Obesities: Future Choices, (2012) URL http://www.foresight.gov.uk/Obesity/Obesity_ final/index.htm (accessed January 2012).

4. A. Costello, M. Abbas, A. Allen, S. Ball, R. Bellamy, S. Friel, , N. Grace, A. Johnson, M. Kett, , M. Lee, C. Levy, M. Maslin, D. McCoy, B. McGuire, H. Montgomery, D. Napier, C. Pagel, J. Patel, J.A.P. de Oliveira, N. Redclift, H, Rees, D. Rogger, J. Scott, J. Stepenson, J. Twigg, J. Wolff and C. Patterson, Managing the health effects of climate change, The Lancet, Vol. 373, (2009)1693-1733.

5. G. Egger, Personal carbon trading: a potential stealth intervention for obesity reduction? Medical Journal of Australia, 187(3), (2007) 185-187.

6. G. Egger Dousing our inflammatory environment(s): Is personal carbon trading an option for reducing obesity and climate change", Obesity Reviews, 9(5), (2008) 456463.

7. O. Faergeman, Climate change and preventive medicine, European Journal of Cardiovascular Prevention \& Rehabilitation, 14(6), (2007) 726-729.

8. S. Roberts, and J. Thumim, A rough guide to individual carbon trading. The ideas, the issues and the next steps, (Centre for Sustainable Energy, UK, 2006).

9. D. Fleming, Energy and the Common Purpose: Descending the Energy Staircase with Tradable Energy Quotas (TEQs). The Lean Economy Connection: London, (2008) URL http://www.theleaneconsomy connection.net (accessed January 2012).

10. T. Fawcet, C. Bottrill, B. Boardman and G. Lye, Trialling personal carbon allowances, Report for the UK Energy Research Centre (UKERC/RR/DR/2007/002), (Oxford University, UKm 2007).

11. House of Commons Environmental Audit Committee, Personal Carbon Trading - Fifth Report of 2007-8, (Stationary Office Ltd., London, May 2008).

12. United Nations (UN), Kyoto Protocol to the United Nations Framework Convention on Climate Change, (New York City, NY, USA, 1998).

13. United Nations Framework Convention on Climate Change (UNFCCC), Caring for the Climate: a guide to the Climate Change Convention and the Kyoto Protocol, (United Nations Framework Convention on Climate Change, Bonn, Germany, 2005).

14. S. Kahn Ribeiro, S. Kobayashi, M. Beuthe, J. Gasca, D. Greene, D. S. Lee, Y. Muromachi, P. J. Newton, S. Plotkin, D. Sperling, R. Wit and P. J. Zhou, Transport and its infrastructure. In Climate Change 2007: Mitigation. Contribution of Working Group III to the
Fourth Assessment Report of the Intergovernmental Panel on Climate Change, B. Metz, O.R. Davidson, P.R. Bosch, R. Dave, L.A. Meyer (eds), (Cambridge University Press, Cambridge, United Kingdom and New York, NY, USA. 2007).

15. P. Edwards and I. Roberts, Population adiposity and climate change, International Journal of Epidemiology, 38(4), (2009) 1137-1140.

16. P. A. Higgins, Exercise-based transportation reduces oil dependence, carbon emissions and obesity, Environmental Conservation, 32(3), (2005) 197-202.

17. P. A. Higgins, and M. Higgins, A healthy reduction in oil consumption and carbon emissions, Energy Policy, 33(1), (2005) 1-4.

18. J. Woodcock, P. Edwards, C. Tonne, B.G. Armstrong, O. Ashiru, D. Banister, S. Beevers, Z. Chalabi, Z. Chowdzury, A. Cohen O.H. Franco, A. Haines, R. Hickman, G. Lindsay, I. Mittal, D. Mohan, G. Tiwari, A. Woodward and I. Roberts, Public health benefits of strategies to reduce greenhouse-gas emissions: urban land transport, The Lancet, 374(9705), (2009) 19301943.

19. P. Hossain, B. Kawar and M. El Nahas, Obesity and diabetes in the developing world-a growing challenge, New England Journal of Medicine, 356(3), (2007) 213215.

20. L.H. Kushi, T. Byers, C. Doyle, E.V. Bandera, M. McCullough, T. Gansler, K.S. Andrews and M.J. Thun, American Cancer Society Guidelines on Nutrition and Physical Activity for cancer prevention: reducing the risk of cancer with healthy food choices and physical activity, CA: a cancer journal for clinicians, 56(5), (2006) 254-281.

21. S.C. Jagers, A. Löfgren and J. Stripple, Attitudes to Personal Carbon Allowances: The effect of trust in politicians, perceived fairness and ideology, Working Papers in Economics 360, (2009) URL http://www.gu.se /english/research/publication/?publicationId=93377 accessed October 2014.

22. B. Taylor, and P. McNiel, Norfolk Island 2011 Census of Population and Housing, Norfolk Island, (2011).

23. W.H. DeLone, and E.R. McLean, Information Systems Success: The Quest for the Dependent Variable, Information Systems Research, 3(1), (1992)60-95.

24. W.H. DeLone, and E.R. McLean, Information systems success revisited, Proceedings of the 35th Hawaii International Conference on System Sciences, (2002) 238-248.

25. W.H. DeLone, and E.R. McLean, The DeLone and McLean Model of Information Systems Success: A TenYear Update, Journal of Management Information Systems, 19(4), (2003) 9-30.

26. V. Venkatesh, M.G. Morris, G.B. Davis, and F.D. Davis, User acceptance of information technology: Toward a unified view, MIS quarterly, 27(3) (2003) 425-478. 
27. F.D. Davis, Perceived usefulness, perceived ease of use, and user acceptance of information technology, MIS quarterly, 13(3), (1989) 319-340.

28. F.D. Davis, R.P. Bagozzi, and P.R. Warshaw, User acceptance of computer technology: a comparison of two theoretical models, Management Science, 35(8), (1989) 982-1003.

29. F.D. Davis, R.P. Bagozzi, and P.R. Warshaw, User acceptance of computer technology: a comparison of two theoretical models, Management Science, (1989). 982-1003.

30. V. Venkatesh, and F.D. Davis, A theoretical extension of the technology acceptance model: Four longitudinal field studies, Management Science, 46(2), (2000) 186204.

31. A. Hendry, G. Webb, A. Wilson, B. Armstrong, W. Smart and G. Egger, Influences on intentions to use a personal carbon trading system (NICHE - the Norfolk Island carbon health evaluation project), The International Technology Management Review, 5(2), (2015) pp. 105-116.
32. D. T. Doherty and Y. Kartalova-O'Doherty, Gender and self-reported mental health problems: Predictors of help seeking from a general practitioner, British Journal of Health Psychology, 15(1), (2010) 213-228.

33. U.W. Jayasinghe, M.F. Harris, J. Taggart, J., B, Christl and D.A. Black, Gender differences in health-related quality of life of Australian chronically-ill adults: patient and physician characteristics do matter, Health and Quality Of Life Outcomes, 11: 102 doi: 10.1186/1477-7525-11-102. (2013).

34. M. Jeffries and S. Grogan, Oh, I'm just, you know, a little bit weak because I'm going to the doctor's: Young men's talk of self-referral to primary healthcare services, Psychology \& Health, 27(8), (2012) 898-915.

35. J.A. Smith, A. Braunack-Mayer and G. Wittert, What do we know about men's help-seeking and health service use?, Medical Journal of Australia, 184(2), (2006) 8183.

36. A.K. Mansfield, M.E. Addis, and J. R. Mahalik, Why Won't He Go to the Doctor?: The Psychology of Men's Help Seeking, International Journal of Men's Health, 2(2), (2003) 93-109. 
Appendix

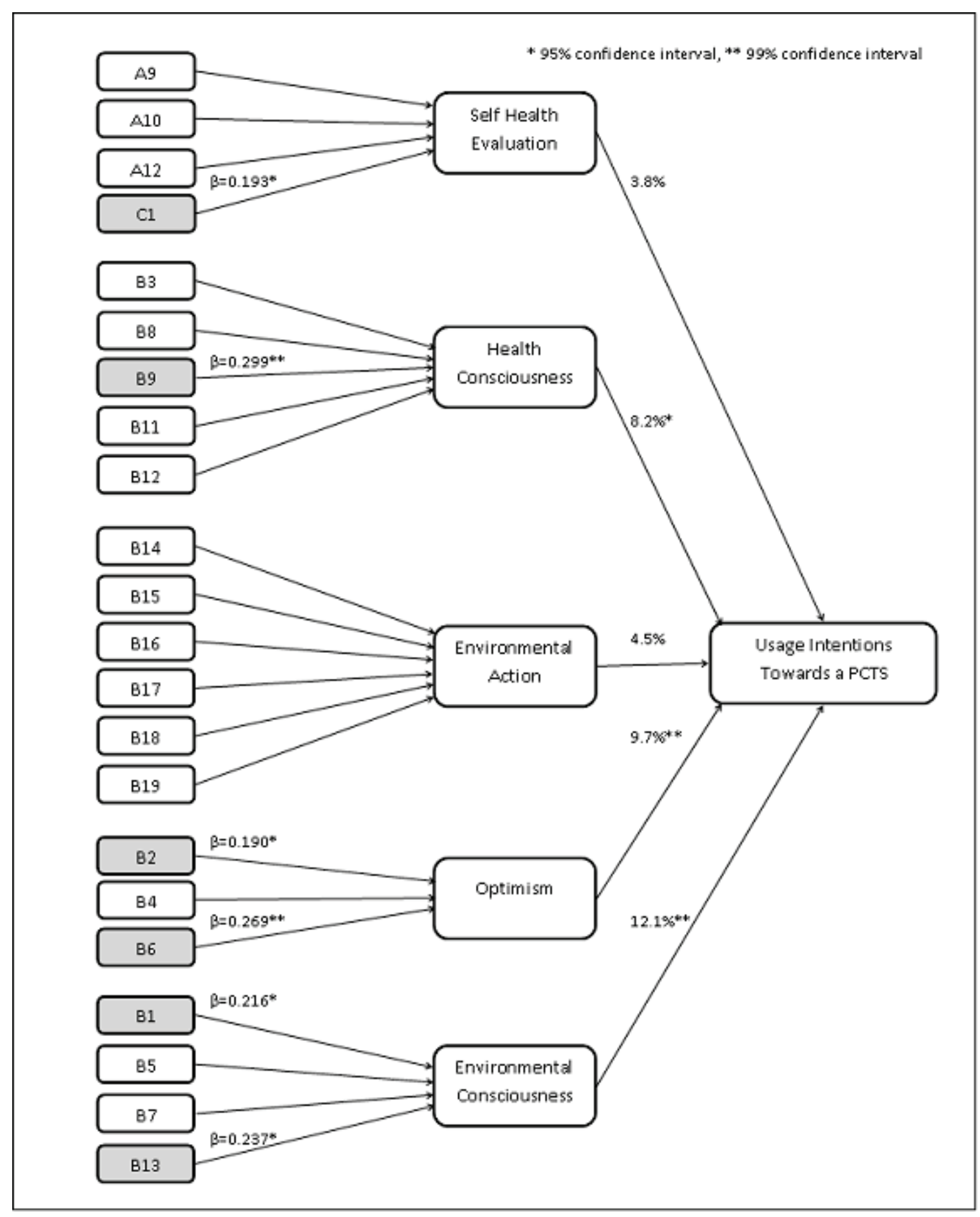

Figure 2. Variance in Usage Intentions towards a PCTS - Males. 


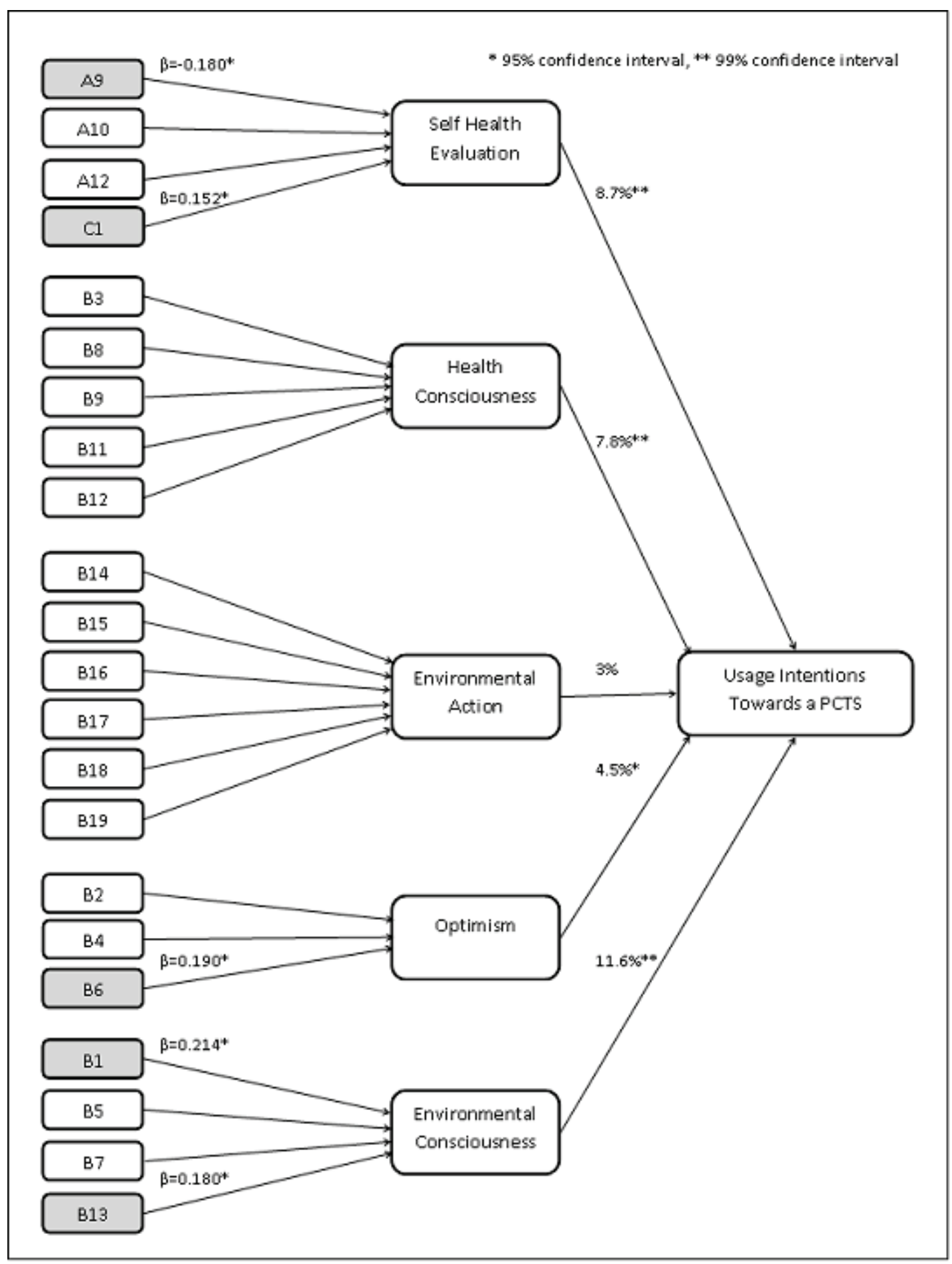

Figure 3. Variance in Usage Intentions Towards a PCTS - Females. 